\title{
Benefits and harms of cervical screening from age 20 years compared with screening from age 25 years
}

\author{
R Landy ${ }^{1}, \mathrm{H}$ Birke ${ }^{1}$, A Castanon ${ }^{1}$ and P Sasieni ${ }^{\star}, 1$ \\ ${ }^{1}$ Centre for Cancer Prevention, Wolfson Institute of Preventive Medicine, Bart's and The London School of Medicine, Queen Mary \\ University of London, Charterhouse Square, London EC1M 6BQ, UK
}

Background: To quantify the benefits (cancer prevention and down-staging) and harms (recall and excess treatment) of cervical screening starting from age 20 years rather than from age 25 years.

Methods: We use routine screening and cancer incidence statistics from Wales (for screening from age 20 years) and England (screening from 25 years), and unpublished data from the National Audit of Invasive Cervical Cancer to estimate the number of: screening tests, women with abnormal results, referrals to colposcopy, women treated, and diagnoses of micro-invasive (stage 1A) and frank-invasive (stage IB + ) cervical cancers (under three different scenarios) in women invited for screening from age 20 years and from 25 years.

Results: Inviting 100000 women from age 20 years yields an additional: 119000 screens, 20000 non-negative results, 8000 colposcopy referrals, and an extra 3000 women treated when compared with inviting from age 25 years. Screening from age 20 years prevents between three and nine frank invasive cancers and between 0 and 23 cancers in total (depending on the scenario). A cumulative increase of nine stage IB + cancers corresponds to an annual rate increase of 0.9 per 100000 women aged 20-29 years.

Conclusions: To prevent one frank invasive cancer, one would need to do between 12500 and 40000 additional screening tests in the age group 20-24 years and treat between 300 and 900 women.

In October 2003, a new policy was announced concerning the age at which women are invited for cervical screening in England. Previously, women were to be invited at least once every 5 years from age 20 to 64 years. The new policy required that all women should be invited three-yearly from their 25th birthday up to age 49 years and five-yearly from age 50 to 64 years. Wales set a policy of three-yearly screening from age 20 years in 1999 and continued unchanged until 2013.

The age from which to start cervical screening remains controversial. European guidelines (Arbyn et al, 2010) recommend that screening 'should start in the age range 20-30 years, but preferentially not before age 25 or 30 years'. Australia starts from age 18 years (or two years after first sexual intercourse, whichever is later) as did America (Saslow et al, 2002). Most US guidelines now recommend that screening starts at age 21 years regardless of the age of onset of sexual activity (Committee on Practice Bulletins-Gynecology, 2012; Moyer, 2012; Saslow et al, 2012), whereas some countries with organised screening programmes (e.g., Finland and The Netherlands) do not invite women until they are 30 years.

Not screening young women remains unpopular. Data from 2010 show that the majority (62\%) of 20 -year-old women in the United States of America are still attending cervical screening (Centers for Disease Control and Prevention, 2013) and a poll on the BMJ website in 2009 found that $65 \%$ (287 out of 443 ) of those choosing to participate were not in favour of stopping screening in women under age 25 years (British Medical Journal, 2009).

Screening guidelines and policies refer to harms and benefits of screening, but they do not provide any figures with which one

*Correspondence: Professor P Sasieni; E-mail: p.sasieni@qmul.ac.uk.

Received 18 October 2013; revised 14 January 2014; accepted 15 January 2014; published online 11 February 2014

(c) 2014 Cancer Research UK. All rights reserved 0007 - 0920/14 
could make an explicit comparison. Here, we aim to quantify the harms and benefits of screening starting from age 20 years compared with starting from age 25 years.

\section{MATERIALS AND METHODS}

We compared offering three-yearly screening in 100000 women starting from age 20 years with starting from age 25 years by considering the following events: number of screening tests, number of women with an abnormal screening test, number of women referred to colposcopy, number of women treated (excision or ablation), number of women with micro-invasive cervical cancer (stage IA), and number of women with frank cervical cancer (stage IB or worse). No attempt was made to estimate the number with anxiety as a result of their screening, nor the number of preterm deliveries as a result of their treatment. Our approach was to estimate the cumulative number of events by using the relevant proportions from published data, combining them as appropriate, and presenting the results per 100000 women invited for screening.

The results are presented in terms of the cumulative number of events over 7 years from age 20 years (until a woman's 27th birthday). Follow-up until age 27 years was used to ensure that women first screened at age 25 years had time to be diagnosed following early recall and because we reasoned that there would be very little difference in results once at least one round of screening had been completed under both policies. Estimation was carried out separately in the age groups 20-24 and 25-26 years and then summed.

We used three types of data: tabular cross-sectional statistics on cervical screening, individual-level longitudinal data on cervical screening, and cancer incidence statistics, from a total of six sources. Routinely published screening data from England and from Wales in the financial year 2011/12 (Cervical Screening Wales, 2012; The NHS Information Centre, 2012) were used for the number of tests taken and the result of these tests (Supplementary Tables 1 and 2). Cancer incidence rates were taken from national statistics (Office for National Statistics, 2013; The Welsh Cancer Intelligence and Surveillance Unit, 2013). In general, we used data from Wales for screening from age 20 years and from England for screening from age 25 years. Since, however, the change in policy in England was only implemented in 2004-2005, women born before 1984 will have been invited from age 20 years even in England.

The number of screening tests that would be carried out, under each policy, between ages 20 and 27 years is based on the proportion of women with at least one adequate test result in a given year (2011/12; see Supplementary Table 1). For Tables 1 and 2, these proportions were multiplied by five for the age group 20-24 years. We assume that with three-yearly screening from age 25 years, half of those screened between 25 and 29 years will be screened at 25 or 26 years. Thus, for screening from 25 years, we multiplied the annual numbers for women aged 25-29 years by 2.5 and by 2.0 for screening from age 20 years.

For the estimation of the non-negative test results in the age group 25-26 years when screening starts from age 25 years, we explicitly took into account the extent to which a first-test is more likely to be non-negative than a test taken in a woman of the same age who was screened previously. Although direct comparison between England and Wales is possible, we were concerned that this would overestimate differences in cytological abnormalities associated with the different policies because cytological abnormality rates tend to be slightly higher (at all ages) in Wales compared with England. Further, assuming abnormality rates in England at ages 25-26 years (on the prevalent screen) were much higher than at ages 27-29 years, the effect would be diluted using the available data for ages 25-29 years combined. Using longitudinal data from the NHS Cervical Screening Programme (NHSCSP) audit of cervical screening in England, we estimated the relative proportion of borderline or mild dyskaryosis in women screened from age 25 years compared with those screened from age 20 years (Supplementary Table 5). The relative risks in Supplementary Table 5 were calculated stratifying on year of test, to allow for the change in the proportion of non-negative results over time, with the strata combined using Mantel-Haenszel weights. The same was done for moderate dyskaryosis or worse. These relative risks were applied to the proportions with the given results in Wales so as to estimate the results of screening from age 25 years.

In the published statistics of the cervical screening programme, there is no age breakdown of the numbers of referrals to colposcopy. To estimate referrals within the age groups, we assumed that all women with a moderate or worse test result and a certain proportion (independent of age) of women with a borderline or mild test result are referred to colposcopy. This proportion is estimated on the basis of a weighted average of data from England and Wales (see Supplementary Table 1, footnote (4)).

There are no good data on the number of women treated. We approximated the number of women treated by the number with CIN2 or worse on histology. As there are no data on histology by age, we assumed that the positive predictive value of a particular cytology result for CIN2 + was the same at all ages. The predictive values are given separately for women referred following a lowgrade result (inadequate, borderline, and mild) and women with a potentially significant abnormality (moderate or worse cytology; see Supplementary Table 2, footnote 4). Most women referred following a low-grade result will have had a second such result whilst on early recall following a first low-grade result.

Table 1. Assumptions for the estimation of excess cancers diagnosed as a result of the change in policy under various scenarios

\begin{tabular}{|c|c|c|c|}
\hline Assumptions & $\begin{array}{l}\text { Observed change in cancer } \\
\text { rates (scenario } 1 \text { ) }\end{array}$ & $\begin{array}{l}\text { Case-control } \\
\text { (scenario 2) }\end{array}$ & $\begin{array}{l}\text { CIN3 progression } \\
\text { (scenario } 3 \text { ) }\end{array}$ \\
\hline A. Stage IA cancer is always occult ${ }^{a}$ & Yes & Yes & Yes \\
\hline $\begin{array}{l}\text { B. Observed changes in rates (relative to those age } 30-34 \text { years) } \\
\text { caused by the change in policy }\end{array}$ & Yes & Not applicable & Not applicable \\
\hline C. Observed stage distribution age $25-26$ years & Yes & Not applicable & Not applicable \\
\hline D. Cancer does not regress & Not applicable & Yes & Yes \\
\hline E. Progression of stage IA to IB to symptomatic IB + cancer & Not applicable & Yes & Yes \\
\hline F. Progression of CIN3 to cancer (by age 25 years) & Not applicable & 0 & $0.2 \%$ p.a. ${ }^{b}$ \\
\hline
\end{tabular}




\begin{tabular}{|c|c|c|c|c|c|}
\hline Data sources & $\begin{array}{l}\text { Age at risk } \\
\text { (years) }\end{array}$ & $\begin{array}{c}\text { Age of data } \\
\text { (years) }\end{array}$ & $\begin{array}{c}100000 \text { Women invited } \\
\text { in Wales }\end{array}$ & $\begin{array}{l}100000 \text { Women invited } \\
\text { in England }\end{array}$ & $\begin{array}{l}\text { Excess in } \\
\text { Wales }\end{array}$ \\
\hline \multicolumn{6}{|l|}{ National statistics for $2010 / 11^{a}$} \\
\hline Screening tests & $\begin{array}{l}20-24 \\
25-29\end{array}$ & $\begin{array}{c}20-24 \\
25-26^{\mathrm{b}} \\
\text { Sum }\end{array}$ & $\begin{array}{c}134961 \\
54857 \\
189818\end{array}$ & $\begin{array}{c}8546 \\
70710 \\
79256\end{array}$ & 110562 \\
\hline Non-negative test results & $\begin{array}{l}20-24 \\
25-29\end{array}$ & $\begin{array}{c}20-24 \\
25-26 \\
\text { Sum }\end{array}$ & $\begin{array}{c}23968 \\
6988 \\
30956\end{array}$ & $\begin{array}{c}1658 \\
9045 \\
10703\end{array}$ & 20253 \\
\hline Moderate dyskaryosis or worse & $\begin{array}{l}20-24 \\
25-29\end{array}$ & $\begin{array}{c}20-24 \\
25-26 \\
\text { Sum }\end{array}$ & $\begin{array}{l}3227 \\
1548 \\
4775\end{array}$ & $\begin{array}{c}270 \\
2189 \\
2459\end{array}$ & 2316 \\
\hline \multicolumn{6}{|c|}{ Average incidence $^{c}$ 2000-2011 for Wales, 2010-2011 for England } \\
\hline Cancers (all) & $\begin{array}{l}20-24 \\
25-29\end{array}$ & $\begin{array}{c}20-24 \\
25-26^{d} \\
\text { Sum }\end{array}$ & $\begin{array}{l}19.7 \\
30.8 \\
50.5\end{array}$ & $\begin{array}{l}12.5 \\
36.7 \\
49.2\end{array}$ & 1.3 \\
\hline \multicolumn{6}{|l|}{ Proportions observed in Audit data ${ }^{e}$} \\
\hline Cancers (stage 1A) & $\begin{array}{l}20-24 \\
25-29\end{array}$ & $\begin{array}{c}20-24 \\
25-26 \\
\text { Sum }\end{array}$ & $\begin{array}{c}7.9 \\
15.0 \\
22.8\end{array}$ & $\begin{array}{c}4.3 \\
21.4 \\
25.7\end{array}$ & -2.8 \\
\hline Cancers (stage 1B + ) including unknowns & $\begin{array}{l}20-24 \\
25-29\end{array}$ & $\begin{array}{c}20-24 \\
25-26 \\
\text { Sum }\end{array}$ & $\begin{array}{l}11.8 \\
15.8 \\
27.6\end{array}$ & $\begin{array}{c}8.2 \\
15.3 \\
23.5\end{array}$ & 4.1 \\
\hline \multicolumn{6}{|c|}{ 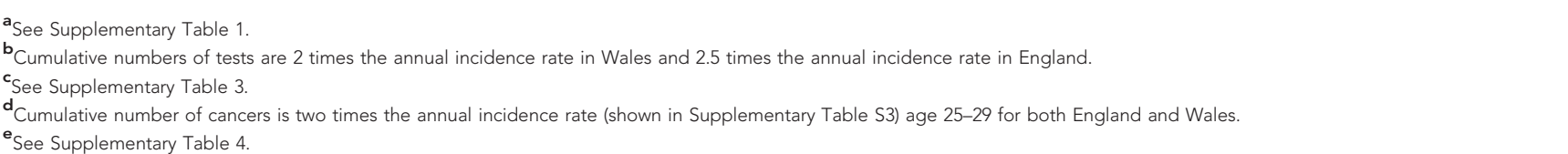 } \\
\hline
\end{tabular}

In the direct comparison between Wales and England, the rates were averaged from 2000-2011 for Wales and for 2010-2011 for England (to include only women first invited at 25 years; Supplementary Table 3 ). As these are annual rates, the numbers were multiplied by 5 to get the cumulative incidence for ages 20-24 years, and by 2 for the cumulative incidence for ages 25-26 years. The numbers of stage $1 \mathrm{~A}$ and stage $1 \mathrm{~B}+$ cancers were calculated by multiplying the total number of cancers by the proportion of cancers diagnosed at the given stage for that age range. These were estimated using cohort data from the NHSCSP audit of invasive cervical cancer in England (Audit of Invasive Cervical Cancer Management Group, in press) and from the Cervical Screening Wales Audit of Cervical Cancer (Sasieni et al, 2013; Supplementary Table 4). In the NHSCSP audit, of those cancers that were initially registered with stage unknown but subsequently had a stage entered, the vast majority were stage IB or worse. We therefore pool cancers of unknown stage with frank invasive cancers for estimation of the proportion of micro-invasive cancer.

We estimated the number of cancers with a policy of starting screening from age 25 years under three different scenarios. A summary of the assumptions made by each scenario can be found in Table 1. Although about $20 \%$ of cancers in women not invited for screening aged 20-24 years were stage 1A (unpublished audit data), we assumed that without screening there would be no stage IA cancers in women aged 20-24 years (assumption A).

Scenario 1 is based on the observed trends in cervical cancer. We compared changes in rates in women aged 20-24 and 25-29 years with those in women aged 30-34 years. Scenarios 2 and 3 involve modelling progression from $\mathrm{CIN} 3$ to stage $1 \mathrm{~A}$ and stage $1 \mathrm{~B}$ cervical cancer. In scenario 2 , it is assumed that no screen-detected
CIN3 would have progressed to cancer by age 25 years (i.e., the total number of cancers remained the same). In scenario 3 , we assume that in women aged $20-26$ years, $0.2 \%$ of CIN3 progresses to cancer each year (Sasieni et al, 2009b). For more details see the Supplementary Methods.

Analyses were done in STATA 12 (StataCorp., College Station, TX, USA).

\section{RESULTS}

The numbers on which estimates are based are summarised in Supplementary Tables 1-5. The main results are presented in Tables 2-4. Table 2 compares the observed impact of cervical screening in 100000 women in England and Wales. Table 3 estimates the impact of the different screening policies on workload (numbers of screening tests, colposcopy referrals, and women treated) and Table 4 estimates cervical cancer under various scenarios.

Numbers of tests. The number of screening tests (counting at most one test per woman per year) in 100000 women aged 20-26 years is estimated to be 110562 higher in Wales than in England (Table 2). Ignoring tests outside of the programme and allowing for more testing exactly at age 25 years, we estimate that the difference that is attributable to the different policies is 119108 (Table 3).

Non-negative results. By age 27 years, there are 30956 nonnegative episodes per 100000 women in Wales. By contrast, only 10703 non-negative episodes are observed in England (Table 2; including 1658 under age 25 years). 


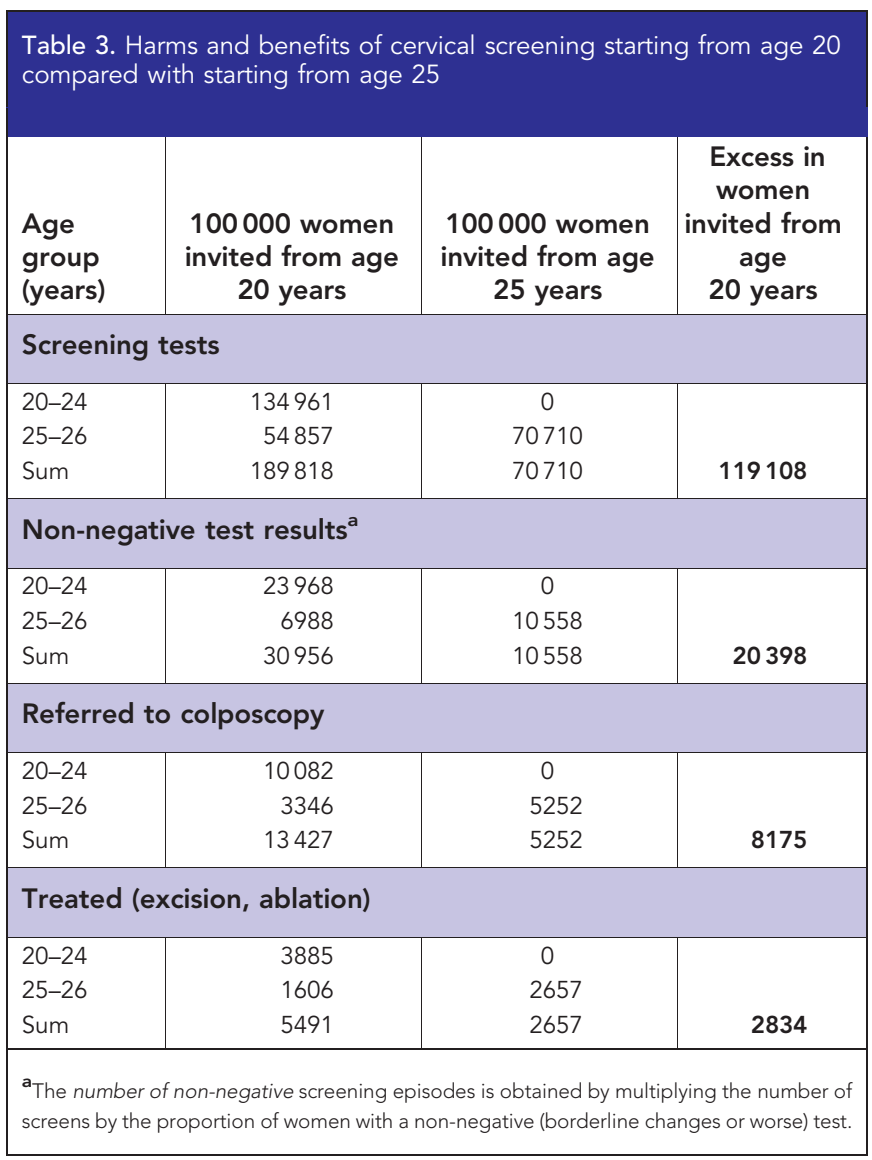

Table 4. Number of cancers diagnosed in a cohort of 100000 women aged 20-26 years (inclusive) under different cancer progression scenarios

\begin{tabular}{|c|c|c|c|c|}
\hline \multicolumn{5}{|c|}{ Invited from age 25 years } \\
\hline $\begin{array}{l}\text { Age } \\
\text { group } \\
\text { (years) }\end{array}$ & $\begin{array}{l}\text { Invited } \\
\text { from } \\
\text { age } 20 \\
\text { years }\end{array}$ & $\begin{array}{l}\text { Cancer rates } \\
\text { (scenario 1) }\end{array}$ & $\begin{array}{l}\text { Case-control } \\
\text { (scenario 2) }\end{array}$ & $\begin{array}{c}\text { CIN3 } \\
\text { progression } \\
\text { (scenario 3) }\end{array}$ \\
\hline \multicolumn{5}{|c|}{ Cancers (all) } \\
\hline $20-24$ & 20.0 & 14.7 & 14.0 & 16.7 \\
\hline $25-26$ & 30.0 & 58.3 & 36.0 & 46.9 \\
\hline Sum & 50.0 & 73.1 & 50.0 & 63.7 \\
\hline \multicolumn{5}{|c|}{ Cancers (stage IA) } \\
\hline $20-24$ & 8.0 & 0.0 & 0.0 & 0.0 \\
\hline $25-26$ & 14.6 & 42.6 & 18.6 & 26.8 \\
\hline Sum & 22.6 & 42.6 & 18.6 & 26.8 \\
\hline \multicolumn{5}{|c|}{ Cancers (stage IB + ) } \\
\hline $20-24$ & 12.0 & 14.7 & 14.0 & 16.7 \\
\hline $25-26$ & 15.4 & 15.7 & 17.4 & 20.2 \\
\hline Sum & 27.4 & 30.4 & 31.4 & 36.9 \\
\hline
\end{tabular}

Despite rates of moderate dyskaryosis or worse at age 25-29 years being higher in England than in Wales (Supplementary Table 1), the cumulative number of women with moderate dyskaryosis or worse by age 27 years is much greater in Wales than in England: about 2316 more cases per 100000 women (Table 2).

In the longitudinal audit data (Supplementary Table 5), the proportion of results that are borderline or mild after adjusting for year of test is $13 \%$ greater in women screened from age 25 years compared with those screened from age 20 years; and for moderate or worse, it is $32 \%$ greater. We applied the weighted relative risks (1.13 and 1.32) to the Welsh proportions (Supplementary Table 1). This yields 10558 non-negative tests by age 27 years in 100000 women invited from age 25 years: 20398 fewer than when screening is offered from age 20 years (Table 3 ).

Colposcopy and treatment. Overall, 33\% of women with a borderline or mild test result were referred to colposcopy (see Supplementary Table 1, footnote (4)). Based on the numbers with low-grade (borderline or mild) and high-grade (moderate or worse) cytology results and referral rates of $33 \%$ for low grade and $100 \%$ for high grade, we estimate that there would be 13427 referrals with screening from age 20 years compared with 5252 with screening from age 25 years (Table 3).

On average (see Supplementary Table 2, footnote (4)), 84\% of women with moderate or worse dyskaryosis on cytology have CIN2 or worse histology (and we assume that they will be treated, as per guidelines (NHS Cancer Screening Programmes, 2010)), and $17 \%$ of women referred to colposcopy with low-grade cytology have CIN2 or worse. We thus estimate that 3885 of 100000 women offered screening from age 20 years would be treated under age 25 years and a further 1606 women at age 25-26 years. Offering screening from age 25 years results in somewhat more being treated at age 25-26 years (2657), but cumulatively reduces the number of women treated by about 2834 per 100000 population (Table 3); that is, $2.8 \%$ of women avoid treatment. As only just over half of women invited are actually screened at age 20-24 years (54.8\% of women aged 20-24 years were tested within the last 5 years in Wales in 2011/12; Cervical Screening Wales, 2012), approximately 1 in 20 of those screened at age $20-24$ years will receive treatment that they would not otherwise have had.

Cervical cancer. The average cervical cancer rates in the age group 20-24 years between 2000 and 2011 were higher in Wales than in England (Supplementary Table 3). Thus, cumulatively there were some 1.3 additional cancers per 100000 women between age 20 and 27 years in Wales than in England (Table 2).

For estimating cancers with screening from age 20 years, we use a rate of 4 per 100000 per year for women aged 20-24 years (which is at the high end of what has been observed in England and Wales) and for women aged 25-29 years, a rate of 15 per 100000 per year (Supplementary Table 3).

The age-specific proportions of cancers that are stage IA with screening from age 20 years are based on audit data for Wales 1999-2009 (see Supplementary Table 4). Audit data from England for 2007-2012 yield similar results. However, more recent data from England show a decline in the proportion of cancers that are stage IA in women aged 20-24 years and an increase in women aged 25-29 years (see footnote (3) and (4) in Supplementary Table 4).

Despite the later start to screening in England, the observed rates of stage IB + cervical cancer are not greater (at ages 20-24 and 25-29 years) than those in Wales (Table 2).

Screening from age 20 years results in eight micro-invasive cancers diagnosed in age group 20-24 years (Table 4). Estimates based on observed increases in cervical cancer rates since the change in policy (scenario 1) resulted in 23 additional cancers diagnosed in age group 20-26 years (total 73). Of these 73 cancers, 43 (58\%) would be micro-invasive. Compared with screening from age 20 years, under this scenario an extra three frank invasive cancers were diagnosed corresponding to a rate increase of 0.3 per 100000 women aged 20-29 years (Table 4). Thus, to prevent one stage IB + cancer (under scenario 1), around 39669 cytology tests will be carried out and an extra 6794 women will have non-negative tests, leading to 2723 referrals to colposcopy and 925 women treated. However, to prevent one cancer (of any stage), one need to do 5156 tests and treat 120 women. 
We have to consider what would happen to cancers screen detected while micro-invasive under age 25 years $(n=8)$ when screening does not commence until age 25 years. Under assumption $\mathrm{E}$, those detected at age 24 years $(n=4)$ would still be micro-invasive when detected at age 25 years; those detected at age 23 years $(n=2)$ would have become stage $1 \mathrm{~B}$ by the time of detection, at age 25-26 years; and those detected at age 20-22 years $(n=2)$ would have become symptomatic stage 1B prior to age 25 years. Thus under the assumption that the total number of cervical cancers diagnosed in the age group 20-26 years remains the same (scenario 2), there is an overall increase of four frank invasive cancers in the age group $20-26$ years. The additional four frank invasive cancers represent a $7.3 \%$ increase in the age group 20-29 years (assuming all the extra cases are aged 20-26 years) compared with women invited from age 20 years. Thus, to downstage one cancer (under scenario 2), around 29777 cytology tests will be carried out, of which around 5100 will be non-negative, leading to an estimated 2044 referrals to colposcopy and 694 women treated.

Allowing for a rate of $0.2 \%$ progression per year from CIN3 (aged 20-24 years) to micro-invasive (scenario 3 ) resulted in a total of 13.7 additional cancers: four micro- and nine frank-invasive (Table 4). This equates to an annual increase in cervical cancer in women aged 20-29 years of 1.4 per 100000 women years and the extra 9.5 stage $\mathrm{IB}+$ cancers to 0.9 per 100000 women years. Thus, to prevent one stage IB + cancer (under scenario 3 ), around 12581 cytology tests will be carried out, of which around 2155 will be non-negative, leading to around 864 referrals to colposcopy and around 299 women treated.

\section{DISCUSSION}

We found that inviting 100000 women for screening from age 20 years would lead to an extra 119000 screens, 20000 extra nonnegative test results, 8000 extra referrals to colposcopy, and extra 3000 women being treated. Compared with starting screening at age 25 years the earlier start may lead to between three and nine fewer stage IB + cancers (depending on the scenario). The overall number of cancers may be reduced by 23.1 but may not change at all. Thus, to prevent one frank invasive cancer, one would need to do between 12500 and 40000 additional screening tests in the age group 20-24 years and treat between 300 and 900 women for cervical intraepithelial neoplasia who would not otherwise be treated.

Our estimates of what happens when 100000 women are offered screening from age 20 years are obtained directly from statistics for Wales and England. As the populations and the screening programmes in England and Wales may not be directly comparable, we have always erred on the side of overestimating both the 'harms' associated with screening from age 25 years and the benefits of screening from age 20 years. In this way, our estimates are likely to put screening from age 20 years in the best possible light. With around $80 \%$ coverage of the HPV vaccination (three doses) in women born since September 1993 in the United Kingdom, the balance of harms and benefits of population screening in women aged 20-24 years will shift further in favour of not screening. We focus on frank-invasive cancer because many IA cancers (70\%) will be treated by cone excision, which is the same treatment offered to women diagnosed with CIN3 (Sasieni and Castanon, 2012).

The assumption that screening women aged 20-24 years does not prevent any cancers in women under the age of 25 years is supported not only by previously published literature (Sasieni et al, 2003, 2009a) but also by available cancer incidence statistics from England and Wales. There has been no obvious increase in cervical cancer aged 20-24 years in England since the change in policy was introduced (Office for National Statistics, 2013). However, rates in women aged 25-29 years in 2010 and 2011 in England have increased and are becoming closer to those observed in Wales. Case-control data suggest that this increase is due to a large number of stage IA cancers diagnosed at age 25 years (Castanon et al, 2013). Nevertheless, it is impossible to assess the full impact of the change in policy on cancer incidence rates in women aged 25-29 in the most recently available data as all women with cancer aged 27-29 will have been invited for screening at age 20 years. Only once women first screened at age 25 years reach the age of 30 years will it be possible to assess whether cancer rates in the age group 26-29 years have decreased leading to overall rates in the age group 25-29 years returning to pre-2009 levels despite the observed increase in cancer at age 25 years.

Given that 5-year relative survival for cervical cancer in England among women aged $20-39$ years is $87.2 \%$ (Trent Cancer Registry, 2012) and that 5- and 10-year relative survival for IB cancer (at all ages) is $88.2 \%$ and $83.1 \%$, respectively (Kosary, 2007), it is likely that at most a small number of women diagnosed with cervical cancer under age 27 years would die from their disease.

We have not estimated the numbers of cancers in the age group 27-29 years under each scenario because we assume that there will be no further advantage of starting screening from age 20 years beyond age 26 years. This is justified because, in recent years, the majority of women screened between ages 24.5 and 27.5 years in England are screened between ages 24.75 and 25.5 years (Castanon et al, 2013). Thus, from age 27 years onwards one is comparing previously screened women regardless of whether screening starts at age 20 or 25 years.

The lack of routinely reported data on which to base our estimates meant that some indirect calculations had to be made. For example, we do not know the proportion of women with moderate or worse dyskaryosis in the age group 20-24 years that are referred to colposcopy, nor do we know how many women are treated. However, our data are not subject to response or recall bias and the same method has been used to estimate these numbers in those screened from age 20 years and from age 25 years.

We have assumed that the relationship between the result of the cytology and that of the histology are independent of age. However, results from HPV trials have suggested that women under the age of 30 years who are HPV positive and cytology positive are more likely to have a histological diagnosis of CIN2 or worse than older women (Kitchener et al, 2009). This would lead to an even greater excess in treatment than we have estimated. In addition, there will undoubtedly be women treated who do not have CIN2 or worse. On balance, however, we believe that the numbers here will be an under-estimate of the true numbers receiving treatment.

It is our view that treatment of 300 women by loop excision of the transformation zone with the ensuing complications $(3.8 \%$ severe haemorrhage in a series of 1000 patients treated in Oxford (Hallam et al, 1993), 0.6\% major complications and 9.1\% minor complications according to one US study (Dunn et al, 2004), 67\% reporting pain according to a UK study (Tombola Group et al, 2009)) is not justified to prevent one case of frank invasive cervical cancer.

The results presented here are specific to the United Kingdom. As abnormality rates (and cancer incidence rates) vary greatly between screening programmes, estimates presented here cannot be extrapolated to other settings. However, where similar data are available, the methodology used here is generalisable.

\section{CONCLUSION}

Estimates of the impact of starting screening at age 25 years compared with age 20 years are based on the best available data. Although there is some uncertainty about the numbers of additional stage IB or worse cancers that are prevented by starting screening 
from age 20 years, it is unlikely to be more than about 1 per 10000 women population. There is far less uncertainty regarding the numbers of screening tests, women with abnormal test results, and women treated at colposcopy as a result of such a policy. To prevent one stage IB or worse cancer, one would need to do between 12500 and 40000 additional screening tests aged 20-24 years and treat between 300 and 900 women for cervical intraepithelial neoplasia. It is only with time that we will be able to tell which of these estimates proves most reasonable. What is clear is that screening from age 20 years leads to substantial over-treatment and has at most a modest impact on cervical cancer prevented.

\section{ETHICAL APPROVAL}

The collection of data as part of this audit has been covered since 2003 by section 251 of the NHS Act 2006 re-enacted Section 60 of the Health and Social Care Act 2001 approval (PIAG 1-08(a)/ 2003). The analysis of anonymised data in this context is considered service evaluation, which does not require research ethics approval according to UK guidelines (NRES; National Patient Safety Agency, 2009).

\section{ACKNOWLEDGEMENTS}

This work is supported by Cancer Research UK (C8162/10406 and C8162/12537). The corresponding author had full access to all the data in the study and had final responsibility for the decision to submit for publication.

\section{CONFLICT OF INTEREST}

The authors declare no conflict of interest.

\section{REFERENCES}

Arbyn M, Anttila A, Jordan J, Ronco G, Schenck U, Segnan N, Wiener H, Herbert A, Von Karsa L (2010) European Guidelines for Quality Assurance in Cervical Cancer Screening. Second edition-summary document. Ann Oncol 21: 448-458.

Audit of Invasive Cervical Cancer Management Group. in press NHSCSP Audit of Invasive Cervical Cancer: National Report 2009-2012. NHS Cancer Screening Progammes: Sheffield, UK.

British Medical Journal (2009) Should we stop screening women under 25 for cervical cancer? BMJ weekly poll. [Online]. Available at http://www.bmj. com/about-bmj/poll-archive (accessed on 10 April 2013).

Castanon A, Leung VM, Landy R, Lim AW, Sasieni P (2013) Characteristics and screening history of women diagnosed with cervical cancer aged 20-29 years. Br J Cancer 109: 35-41.

Centers for Disease Control and Prevention (2013) Cervical Cancer Screening Among Women Aged 18-30 Years-United States, 2000-2010. Morbidity and Mortality Weekly report (MMWR). [Online]. Available from: http://www.cdc.gov/mmwr/preview/mmwrhtml/mm6151a2.htm.

Cervical Screening Wales (2012) Cervical Screening Programme, WALES: 2011/2012. [Online]. Available from: http://www.screeningservices.org/ csw/prof/reports/index.asp.

Committee on Practice Bulletins-Gynecology (2012) ACOG Practice Bulletin Number 131: screening for cervical cancer. Obstet Gynecol 120: $1222-1238$.

Dunn TS, Killoran K, Wolf D (2004) Complications of outpatient LLETZ procedures. J Reprod Med 49: 76-78.

Hallam NF, West J, Harper C, Edwards A, Hope S, Merriman H, Pandher KS, Pinches P, Slade R, Marsh G, Charnock M, Gray W (1993) Large loop excision of the transformation zone (LLETZ) as an alternative to both local ablative and cone biopsy treatment: a series of 1000 patients. J Gynecol Surg 9: 77-82.

Kitchener HC, Almonte M, Thomson C, Wheeler P, Sargent A, Stoykova B, Gilham C, Baysson H, Roberts C, Dowie R, Desai M, Mather J, Bailey A, Turner A, Moss S, Peto J (2009) HPV testing in combination with liquidbased cytology in primary cervical screening (ARTISTIC): a randomised controlled trial. Lancet Oncol 10: 672-682.

Kosary CL (2007) Cancer of the Cervix Uteri. In Ries Lag, Young Jl, Keel GE, Eisner MP, Lin YD, Horner MJ (eds). SEER Survival Monograph: Cancer Survival Among Adults: U.S. SEER Program, 1988-2001, Patient and Tumor Characteristics. National Cancer Institute, SEER Program, NIH Pub No: Bethesda, MD 07-6215.

Moyer VA (2012) Screening for Cervical Cancer: U.S. Preventive Services Task Force Recommendation Statement. Ann Intern Med 156(12): 880-891.

National Patient Safety Agency (2009) NRES Leaflet: Defining research. [Online]. Available at http://www.nres.nhs.uk/applications/is-yourproject-research/.

NHS Cancer Screening Programmes (2010) Colposcopy and Programme Management. In: Luesley D, Leeson. S (eds). Guidelines for the NHS Cervical Screening Programme, publication 20. 2nd ed. NHS Cancer Screening Programmes: Sheffield, UK.

Office for National Statistics (2013) Cancer statistics registrations, England (Series MB1) 1975-2011. Series MB1. Office for National Statistics: London.

Sasieni P, Adams J, Cuzick J (2003) Benefit of cervical screening at different ages: evidence from the UK audit of screening histories. $\mathrm{Br} J$ Cancer 89 : 88-93.

Sasieni P, Castanon A, Cuzick J (2009a) Effectiveness of cervical screening with age: population based case-control study of prospectively recorded data. BMJ 339: b2968.

Sasieni P, Castanon A, Parkin DM (2009b) How many cervical cancers are prevented by treatment of screen-detected disease in young women? Int J Cancer 124: 461-464.

Sasieni P, Castanon A (2012) NHSCSP Audit of Invasive Cervical Cancer: National Report 2007-2011. Sheffield. Available from: http:// www.cancerscreening.nhs.uk/cervical/publications/nhscsp-audit-invasivecervical-cancer.html.

Sasieni P, Castanon A, Beer H (2013) Cervical Screening Wales Audit of Cervical Cancer (CSWACC) National Report: 1999-2009. Available from: http://www.screeningservices.org.uk/csw/prof/reports/index.asp\#cswacc.

Saslow D, Runowicz CD, Solomon D, Moscicki AB, Smith RA, Eyre HJ, Cohen C. American Cancer Society (2002) American Cancer Society Guideline for the early detection of cervical neoplasia and cancer. CA Cancer J Clin 52: 342-359.

Saslow D, Solomon D, Lawson HW, Killackey M, Kulasingam SL, Cain J, Garcia FA, Moriarty AT, Waxman AG, Wilbur DC, Wentzensen N, Downs Jr LS, Spitzer M, Moscicki AB, Franco EL, Stoler MH, Schiffman M, Castle PE, Myers ER (2012) American Cancer Society, American Society for Colposcopy and Cervical Pathology, and American Society for Clinical Pathology screening guidelines for the prevention and early detection of cervical cancer. CA Cancer J Clin 62(3): 147-172.

The NHS Information Centre (2012) Cervical Screening Programme, England: 2011-12. Available from http://www.cancerscreening.nhs. $\mathrm{uk} /$ cervical/statistics-bulletin.html.

The Welsh Cancer Intelligence and Surveillance Unit (2013) Cancer Incidence in Wales: 1975-2011. Data were provided by the Welsh Cancer Intelligence and Surveillance Unit on request, April 2012. Similar date are available from http://www.wales.nhs.uk/sites3/page.cfm?orgid=242\&pid=59080.

Tombola GroupSharp L, Cotton S, Cochran C, Gray N, Little J, Neal K, Cruickshank M (2009) After-effects reported by women following colposcopy, cervical biopsies and LLETZ: results from the TOMBOLA trial. BJOG 116: 1506-1514.

Trent Cancer Registry (2012) Profile of Cervical Cancer in England: incidence, mortality and survival. Sheffield. Available from: http://www. cancerscreening.nhs.uk/cervical/cervical-cancer-profile.html.

This work is published under the standard license to publish agreement. After 12 months the work will become freely available and the license terms will switch to a Creative Commons AttributionNonCommercial-Share Alike 3.0 Unported License.

Supplementary Information accompanies this paper on British Journal of Cancer website (http://www.nature.com/bjc) 